\title{
Non-destructive studies of prehistoric lithic material culture in the search for sources of geologic raw materials: an overview of techniques and issues
}

\section{Estudios no destructivos de cultura material lítica prehistórica en busca de las fuentes del soporte geológico: una revisión de técnicas y cuestiones}

\author{
XAVIER, P. ${ }^{1}$ Y ALVES, C. ${ }^{2 *}$ \\ ${ }^{1}$ LandS/Lab2PT - Laboratório de Paisagens, Património e Território, Universidade do Minho, Braga, \\ Portugal. \\ ${ }^{2}$ LandS/Lab2PT - Laboratório de Paisagens, Património e Território (FCT UID/AUR/04509/2013; \\ FEDER COMPETE POCI-01-0145-FEDER-007528) e Dept. Ciências da Terra/Escola de Ciências, \\ Universidade do Minho, Braga, Portugal \\ *Contacto: casaix@dct.uminho.pt
}

https://doi.org/10.17979/cadlaxe.2019.41.0.5820

enviado: 2/2/2019 aceptado 23/7/2019

\begin{abstract}
Geological raw materials are an important component of the archaeological record in the Prehistory (namely due to their persistence under buried conditions) and pinpointing their original position on the geological context could give important information about activities of ancient human groups. However, archaeological lithic artefacts impose strict restrictions on analytical procedures due to the need to preserve features with cultural meaning, which might affect the effectiveness of the analytical procedure. We attempt here a critical overview of non-destructive techniques for the search of the source of geological raw materials used to make prehistoric lithic artefacts, highlighting issues involved in the interactions between techniques and study objects. It is emphasized that the success of provenance studies will strongly depend on the sensitivity of the analyses undertaken to the characteristics of the sample, as well as the geological information available.
\end{abstract}


Keywords: Geological objects; archaeological artefacts; materials studies; procurement studies

\section{Resumen}

Las materias primas geológicas son un componente importante del registro arqueológico de la Prehistoria (debido a su persistencia en condiciones de enterramiento) y la determinación de su posición original en el contexto geológico podría proporcionar información importante sobre las actividades de los antiguos grupos humanos. Sin embargo, los objetos líticos arqueológicos imponen restricciones estrictas a los procedimientos analíticos debido a la necesidad de preservar elementos con significado cultural, lo que podría afectar a la eficacia del procedimiento analítico. Esta publicación intenta presentar una visión crítica de las técnicas no destructivas para la pesquisa de las fuentes de materias primas geológicas utilizadas en la fabricación de artefactos líticos prehistóricos, resaltando los problemas relacionados con las interacciones entre las técnicas y los objetos de estudio. Se subraya que el éxito de los estudios de procedencia dependerá en gran medida de la sensibilidad de los análisis realizados a las características de la muestra, así como de la información geológica disponible.

Palabras clave: Objetos geológicos; objetos arqueológicos; estudios de materiales; estudios de adquisición 


\section{INTRODUCTION}

Raw material procurement strategies are, nowadays, a major subject in the study of prehistoric lithic industries. While for approximately a century studies of Prehistoric lithic material culture were dominated by typological classification, in the last quarter of the 20th century more systematic approaches were developed, such as the study of the economy and management of raw materials. This kind of studies gains particular importance amidst technological approaches proposed by the ethnology of the French school (LEROI-GOURHAN, 1984a,b; GENESTE, 1991) and by the systematic perspective of processual archaeologists (BINFORD, 1965, CLARKE, 1968). They provide, ultimately, insights into the analysis of economic systems and the understanding of behavioural perspectives (INIZIAN ET AL., 1999).

In simple terms, we can say that the comprehension of the analysis and management of raw materials enables us to recognize and categorize the different raw materials used by a specific community, identify their sources and understand how they were brought to the archaeological site (ODELL, 2000). At the same time, and, in a broader perspective, this line of research, reports to questions such as territories, mobility patterns, routes of circulation, zones of influence, exchange and social interaction, among many other issues, that are fundamental for a better understanding of past human behaviours (INIZIAN ET AL., 1999).

The distinction between raw materials of local origin and exotic materials will be of special importance, as it will allow us to research potential processes of lithic exchange, social interaction between human groups and eventually, to recognize the main axes in exchange networks.

The establishment of the provenance of materials can be also important for experiments in lithic technology (experimental archaeology), in which identical techniques and raw materials from the ancient times will be used to recreate the different stages of creation of a lithic artefact, as well to understand the physical and mechanical properties of different stone and mineral raw materials in a perspective of knapping activities and the choice between different technological strategies (INIZIAN ET AL., 1999). They would be useful also to achieve a broad perspective of the "chaine(s) operatoire(s)" or reduction sequences used by prehistoric communities and to infer relevant behavioural aspects of these human groups, such as mobility routes (INIZIAN ET AL., 1999). Additionally, the recreation of older prehistoric techniques could be valorized in terms of environmental impact and sustainability (given its much lower impact; e.g. its, in general, almost null $\mathrm{CO}_{2}$ emissions). It can be also useful to construct narratives with potential tourist appeal (as the many, more or less serious, examples of the "paleolithic diet" show), for extreme activities with low impact on the terrains.

In this paper we want to consider two main aspects: the first one concerns the challenges that are faced in the search for the source of raw materials used for making archaeological artefacts; and the second one about the merits and inconveniences of different laboratory non-destructive characterization tools. The kind of studies considered here, presents a two-way relation with other study fields in the sense that, on the one hand it will benefit from those studies, namely forensic studies, but, in the 
other hand, provenance studies of archaeological artefacts can also help to test the limits of characterization techniques and promote new developments. In this way, it will be possible to promote the interest of archaeological studies for the natural and hard sciences, especially in the perspective of materials characterization. While it is intended to present a discussion with a wide application, one of our case studies will be used to illustrate some of the points under consideration (and it will be the source of all the images in this paper).

The case study that will be used here as illustration concerns artefacts unearthed in an archaeological excavation performed in a prehistoric shelter located in Cabreira Mountain (Portugal), a region dominated by diverse granite facies with some Quaternary alluvial deposits. Dating of charcoal samples recovered from the excavation indicated a lower limit of human corresponding to the Mesolithic (MEIRELES, 2013). Twentyfour thousand artefacts, amongst several technological categories, such as debris, cores, artefacts, tools, debitage products, etc. were found. Despite the presence of some exogenous lithological resources, the great majority of this set of objects was manufactured of local resources, mainly different varieties of quartz (MEIRELES, 2010).

In the next section, we consider both the problem of source assessment and the essential tension between information gathering and preservation in the case of archaeological artefacts. This will be followed by a section discussing the main issues concerning the use of diverse characterization techniques for the study of geological raw materials used in the making of prehistoric tools.

\section{The sourcing problem}

The sourcing problem in our context concerns the association of a given archaeological object to a specific location for the raw material. We will consider raw materials used in the preparation of prehistoric artefacts but these provenance considerations can be extended to cultural objects without historical information (and when one wants to test historical data regarding origins for the materials).

It will be necessary to define a typology of geological raw materials based on mineralogical and petrographic criteria. The hypotheses concerning sources will depend on the comparison of types with geological objects based on the available geological information. But even when for a type of raw material that is similar to geological objects of a given place, one cannot exclude the possibility of the use of objects from other places, for example, because a given type occurs over a wide area or because there are elsewhere extremely similar types (from the mineralogical or petrographical point of view). In the case study that is being used here for illustration, there are diverse artefacts made of quartz and the available geologic mapping indicates the presence of several quartz veins and pegmatite bodies in the surrounding areas. In the absence of some kind of limiting information, the set of potential sources, in practice, tends towards infinity and hence it is necessary to define criteria that establish a discrete (countable) set of possible places for comparison with the archaeological objects (but there is also the potential for variation within a given geological body), such as a distance range (possible migration paths will be even better). However, this compari- 
son can be useful to reject a given hypothesis when a proposed source fails a test concerning the expected results.

The search for potential sources is affected by the available geological information. Not all regions are covered by detailed geological mapping and even where that mapping exists the kind of information included might be insufficient for assessing the potential sources (for example whether mapped quartz occurrences contain a certain type of quartz). For example, in a (older) geological map in a region near the location of the site of our case study, there is a marked absence of pegmatite bodies (but a more recent map, with a smaller scale, indicates the occurrence of diverse pegmatite bodies). Hence, in some cases, "ad hoc" geological surveys could be necessary. Additionally, the published information has been collected in modern times and some sources of geological materials used in the pre-historic past could not be accessible at that time and places recorded in the geological mapping might not be available at the present time.

It will be also interesting to consider the distribution patterns of archaeological objects in the excavation site. This could be especially useful for archaeological artefacts such as microliths and the wastes of their preparation as it can contribute to discuss whether a given set of these objects came from the same geological raw material.

After the identification of potential sources, geological samples need to be obtained from them. The characterization of these samples is carried out through laboratory methods and techniques, having in mind the comparison between archaeological artefacts and geological samples. This assessment could involve qualitative features, quantitative measurements or both.
In terms of qualitative features, the presence of a given mineral phase or textural or structural feature can, in favourable conditions, rule out some potential sources in the case of the absence of those features. However, this could be disturbed by geological variations and scale effects due to some extreme difference in size (for example, for our case study, between a microlithic quartz tool and a quartz vein).

For quantitative parameters, statistical methods can be applied for univariate and multivariate comparisons, based on location and dispersion measures, which highlights the need to have diverse measurements in any given potential source and, at least idea1ly, also in the archaeological artefacts. The differences between diverse potential sources need to be higher than the variation within potential sources and the series of results from the archaeological artefact will, ideally, fit in the range of results of one of the potential sources or at least clearly near it (and away from the others). Parametric and nonparametric tests can be used to assess these comparisons. One can also use multivariate distance techniques such as principal component analysis or cluster analyses, aiming to assess whether the results of the archaeological artefacts joint the results of one of the potential sources.

\section{Non-destructive characterization - general issues}

When we are dealing with archaeological material, properly contextualized from a stratigraphic point of view, its rarity or even uniqueness, urge us to avoid any damage to them beyond those already experienced while buried (GARRISSON, 2003). As such, non-destructive methods will always be fa- 
voured and only in exceptional circumstances we will contemplate the use of destructive methods.

Efficiency hence becomes a key-word in the choice of methods to apply; efficiency in the sense of the amount and usefulness of the information gathered with those methods without causing damage to the sample. However, other factors, equally important, may influence the choice of a method or technique, such as laboratories availability (logistical issue) and operational costs (financial issue).

Most of the times, only in exceptional circumstances will archaeologists allow the application of destructive methods. These include techniques that require the cut or fragmentation of the sample and even its polishing (as this can affect cultural information of the archaeological sample). For this to happen, it is vital that the information obtained from the application of these methods is such an outstanding one that will compensate for all the damage upon the artefact.

The non-destructive nature of a method may be seen in a dual sense. First, in the sense of avoiding any change that is detectable at the level where the object is read, which will be generally with the naked eye (but some details related to the studied object use or making might involve higher magnifications and, nonetheless, need to be preserved). Additionally, the expression nondestructive can be used, also, in the sense of being reproducible, i.e., allowing several instances of the same technique (repetitions) or the use of different tests or analyses in the same artefact (and even in the same zones of the artefact). If, in a hypothetical situation, for some reason, it is inevitable that the application of a destructive technique, it will be advisable to choose the laboratory procedure that permits the repetition of analyses on the same sample, avoiding further cutting or fragmenting the original archaeological artefact.

Dealing with these questions, one might think that it would be easier to sacrifice items that, eventually, can be considered less important, such as the debris from the making of lithic tools or the cores from which the tools were prepared. This option might be applied in some situations (not without criticism, taking into account the controversial subjective evaluation of the objects extracted from archaeological excavations), but it can have the added problem of introducing another conditional hypothesis (it assumes that these different kinds of objects come from the same kinds of raw material) and limiting the random selection of the analysed entities, which is a basic principle of statistical studies.

Since it is intended to compare the results of archaeological pieces with those of potential geological sources, it will be a sound principle to start the analyses with samples of one of the potential geologic sources, in order to test the impact and efficiency of the proposed techniques. The characteristics of the archaeological objects should be considered, namely the general type of geological raw material (techniques suitable for chert tools might not be efficient for quartz tools and vice-versa due to differences in chemical variations range and transparency, among others) and their geometrical characteristics, both in size and morphology (as the results of diverse techniques are affected by the amount of the sample and by morphological and surface irregularities). Some technological categories found in excavations, such as cores, might assume dimensions that 
are too large for certain analyses or tests. In the case of microlithic artefacts, the available amount might be insufficient to obtain significant results.

Among destructive laboratory analytical techniques, there are a few that could be considered, when the amount of the piece destroyed is no bigger than a few cubic micrometres. With this order of magnitude, the "destruction" that occurs is not significant or impactful, even for microlithic artefacts. Of course, there remains the other issue of being possible to repeat the analyses, which will not be possible on the portion that was consumed but could be done in other portions (the repetition of analyses that consu- me an insignificant portion of the sample run the risk of, somewhere along the line, having a significant impact).

Another issue to keep in mind concerns the contamination that the archaeological remains might have suffered from being buried. Some remains can be often found with their surface contaminated or even slightly distorted. This condition can undermine the analytical characterization and therefore, the provenance reconnaissance. The image in Figure 1 shows a sample of chert where we can recognize on the surface several carbon-rich particles, (of presumably organic contamination during burial).

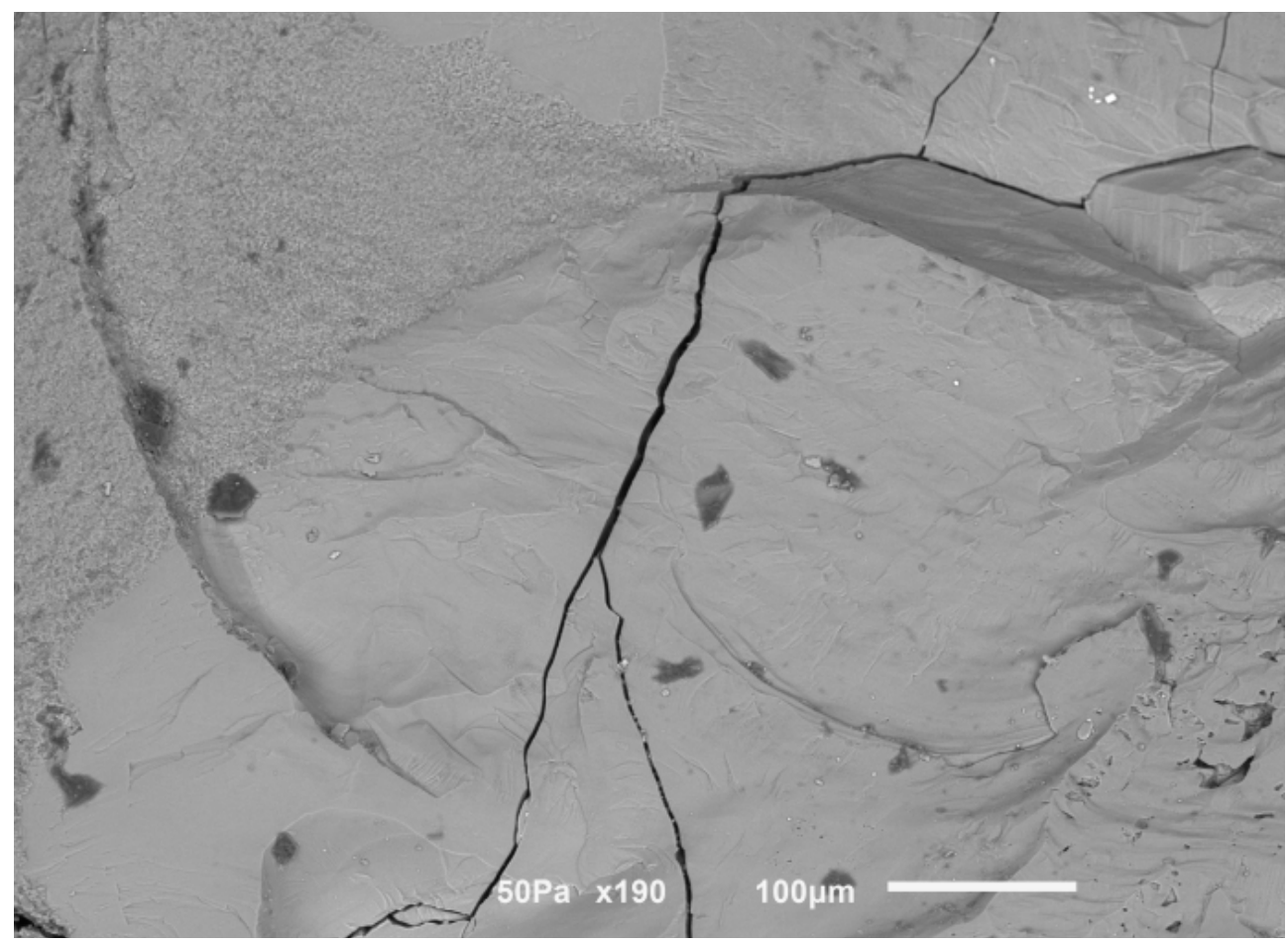

Fig. 1. Scanning electron microscopy showing the presence of contamination by organic particles at the surface of a chert debitage debris. Image obtained at the 3B's laboratory of the AvePark (Portugal) with a JEOLSM-6010LV. 


\section{CHARACTERIZATION TECHNIQUES}

This section will be organized around mineralogical and petrographical studies (which will include morphological, textural and structural issues of the whole geological object), physical techniques (based on contrasting physical characteristics) and chemical analyses, which will include questions related to the presence and proportions of atoms of chemical elements (including isotopes) as well as bonds between them (which might give specific signatures).

\section{Mineralogical and petrographic characteriza- tion}

The usual use of "lithic material culture" in archaeology encompass in practice a relatively restricted range of materials that nonetheless comprise both isolated pure minerals (sometimes fragments of a single crystal), which nonetheless can present patterns of physical and chemical variations, objects usually considered as rocks but that do not have a crystal structure (obsidian), to more complex objects such as flint and aggregates of particles of the same different chemical substances with different structural characteristics (different crystal structures and even amorphous substances), which might present different patterns of physical and chemical variation.

Mineralogical and petrographic studies are the indispensable first step in the provenance assessment. In this way, it is possible to define some kind of typology of geological objects and in this way propose some restriction criteria regarding the geological environment where the raw material could occur and, therefore, some limits on the set of potential sources. It will be especially in- teresting to search for telltale features such as colour features, inclusions (mineral and fluid), fossils, etc.

The mineralogical and petrographic characterization includes, implicitly, the assessment of the homogeneity and heterogeneity of the archaeological artefact, namely whether it is a continuous homogeneous medium, it is formed by an aggregate of particles or present patterns defining different portions (as is the case of the example in Figure 2).

For heterogeneous objects, it will be necessary to characterize the different portions (namely whether they have the same constituent or not and the size and morphology of the particles) and patterns regarding their distribution and orientation. This assessment will be critical to the definition of the analytical program to be applied, namely the selection of characterization techniques (that must be sensitive to the relevant variations in the specific raw material under study) and how to apply them. For example, if the artefact is a heterogeneous mixture of diverse substances, one must be aware that any bulk measurement will be affected by the variations in the proportion of the constituents and it might be of interest to perform analyses on each phase to assess its variations. Still, under the subject of heterogeneity, one can include the presence of solid and fluid inclusions, which might provide data to distinguish from potential sources (COUSSERAN, 2000). For at least some cases, this would be an interactive endeavour as the results of physical, chemical and structural analyses could contribute to the mineralogical and petrographic characterization.

Besides visual studies, other techniques can be used for the characterization of pha- 
ses. X-ray microtomography (HANSFORD ET AL., 2017) allows obtaining a non-destructive 3D evaluation of textures for aggregates of particles of substances that present a contrast in density (as well as pores and fissures). Another method based on X-rays and that can help in the study of textural features is X-ray diffraction (MANNES ET AL., 2015) based on the "reflection" of Xray by crystal planes (defined by a periodic spatial distribution of atoms). This method could give indications on grainsize distribution, the preferred orientation of particles in a polycrystalline object and even indications of the presence of constituents with differences in terms of internal structure. However, its application to objects with irregular surfaces requires special care. X-ray diffraction is related to the arrangement of atoms in periodic structures and it could be useful for assessing whether the material is crystalline and even to identify the crystal substances present in raw material (if there are few different structures) or even test the presence of a given crystal substance.

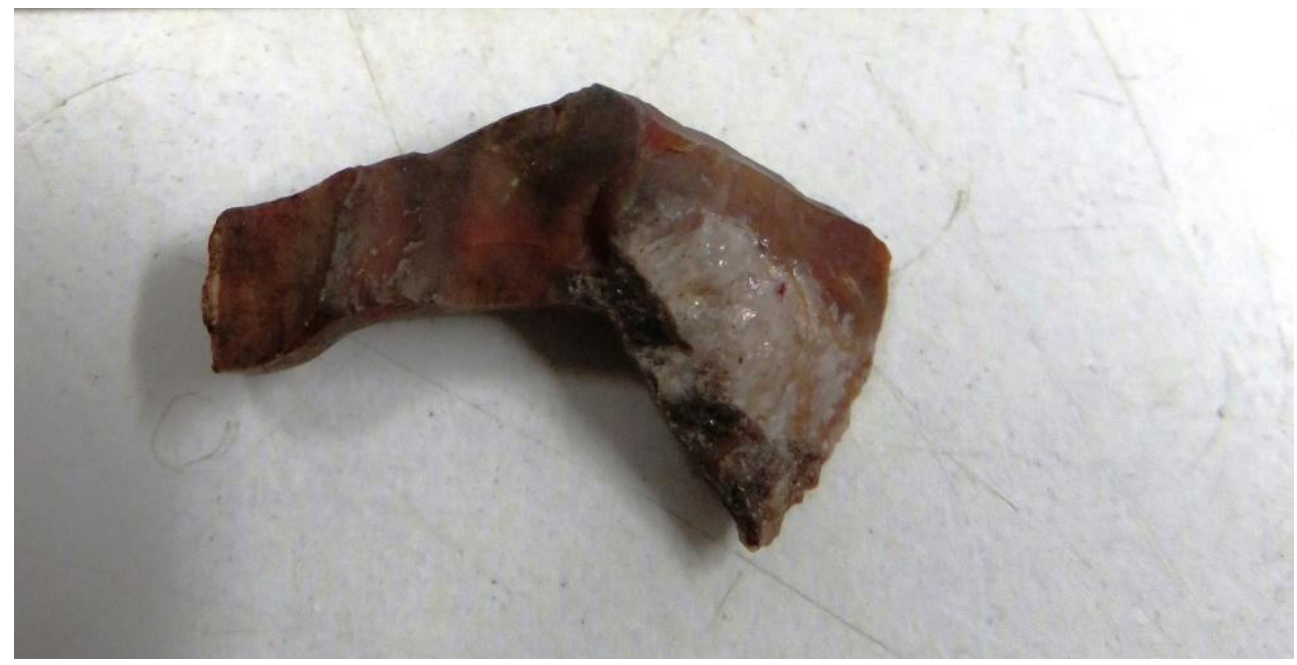

Fig. 2. Chert debitage debris showing heterogeneity.

\section{Physical properties}

Diverse physical properties can contribute to the distinction between geological objects and, besides, be related to mineralogical, textural and chemical features that will also contribute to this end (contributing to the planning of the analytical program).

The most interesting properties in the perspective of the search for sources con- cern the interaction of the minerals with radiation (namely in the visible portion of the spectrum). In the previous section, there was already a reference to the use of radiation for mineralogical and petrographic characterization and many examples of the following section (chemical analyses) concern the use of radiation to obtain information on the presence of atoms in the artefact. The focus here will the global results of proper- 
ties related to interaction with radiation, namely colour and refringence.

Absorption and reflection affect both colour and transparency. The perceived colour and transparency will depend, as we have already mentioned, of the object thickness but as well of the illumination conditions, as is indicated by the BeerLambert law. It will be important to assess also whether the object is homogeneous or not in terms of colour (as well as trans- parency), which will help to plan further analytical work (e.g., colour variations in minerals are frequently related to chemical variations; transparency variations can result of the presence of micro-inclusions). In Figure 3, we present a set of different lithic artefacts in quartz from our case study. Colour observations allow establishing a typology of quartz raw materials that can help in the definition of the set of potential sources.

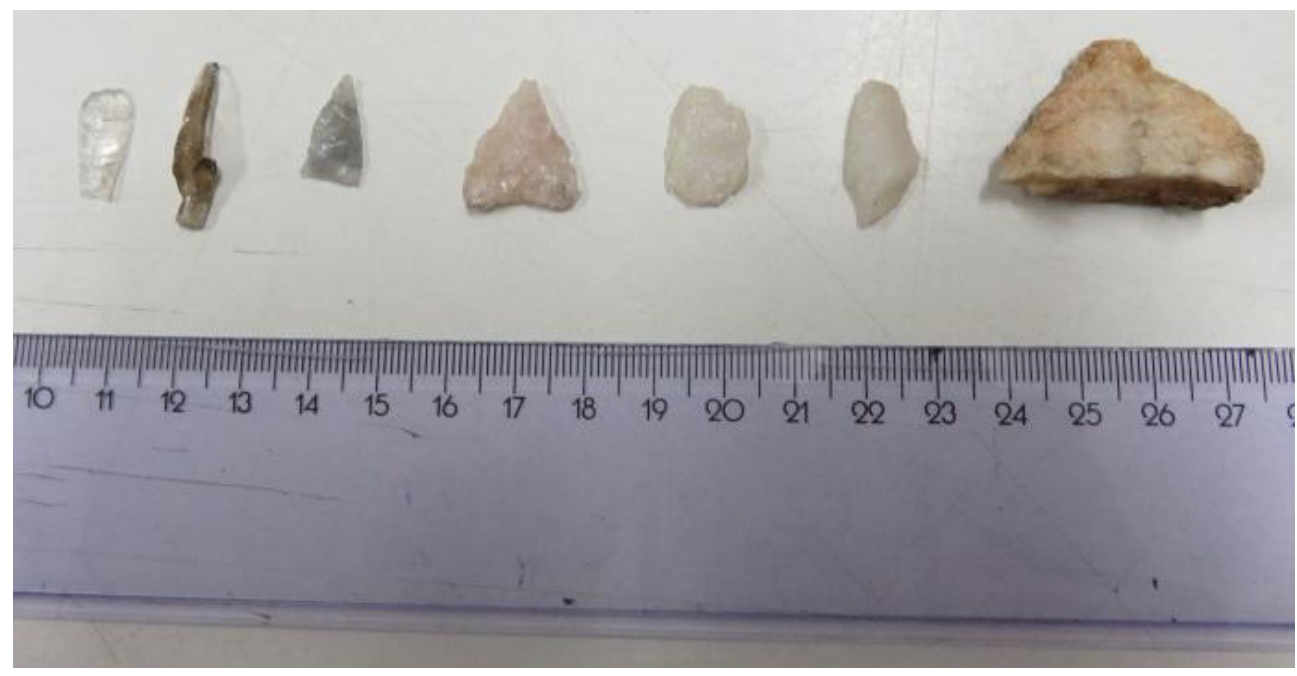

Fig. 3. Lithic artefacts made from quartz (colour variations can be used for a proposal of quartz typology).

Colour can be assessed with the naked eye using the Munsell Colour System, which is constantly used in archaeological excavations in the description and to distinguish different archaeological layers.

But there are instrumental procedures to assess colour either by transmission or by reflection. Hyperspectral analysis (LIANG, 2012) measures reflectance values for different wavelengths from which can be calculated chromatic coordinates CIEL*a*b*, allowing in this way to obtain a quantitative assessment that is reproducible and objective. It is critical to consider the conditions of acquisition, lighting, thickness, roughness as well as heterogeneity (namely in relation to the measuring area). There are presently even smartphone apps that show the chromatic coordinates in these coordinates and, when having some control on acquisition conditions could be an improvement in relation to naked eye assessments in terms of objectivity and reproducibility (under the same illumination conditions, it is ex- 
pected that the same equipment would, for the same colour characteristics, produce the same results).

Studies related to refraction, such as refraction index can also be helpful in the characterization of archaeological material. There is an established tradition of measuring refraction index in a non-destructive fashion (very common in gemological studies). Optical methods are suitable for assessing, besides colour, refringence contrasts in polycrystalline aggregates (indicating the presence of different substances) and even refringence comparison of different constituents by the Becke line and their comparison with media of known refraction index. Petrographic microscopes will have the added interest (in relation to other light microscopes) to allow the study of interference colours which could give information whether the object is monocrystalline or polycrystalline and trends in crystal orientation of the archaeological object, assessments that could give information on the relation between raw material and technique (for example, for an artefact made from a quartz crystal how the geometrical features of the artefact are related to the shape of the crystal).

Spontaneous radiation emission from archaeological artefacts also could be potentially useful in a distinction of potential sources. However, the typical masses and radioisotope concentrations of lithic tools make it difficult to obtain substantial differences. But, at least theoretically, there are minerals that present variations in radioisotopes that could be studied with suitably sensible equipment (spontaneous radiation emission will be discussed again in the context of chemical characterization).

Other physical properties can be determined by non-destructive techniques for most archaeological lithic tools and can help in mineralogical identification as well as to compare samples, namely those concerning the relations between mass and volume such as volumic mass (some minerals can show variations in this property due to variations in the chemical composition) and porosity (related to textural variations).

\section{Chemical Analyses}

Chemical analyses could aim to detect the chemical elements that are present in a sample (qualitative analysis), comparative amounts (ranked analyses, i.e. whether a given chemical element occurs in higher amounts than others) and obtaining values for the amounts of these elements in the sample (quantitative analysis), including isotopic analyses, when they are used for discussing possible sources, as well as information on signatures of internal structure features related to bonds between atoms.

The question of the detection of chemical elements is affected by the chosen technique, namely its sensitivity, including the incapability of some techniques to detect certain elements, as happens with techniques like scanning electron microscopy or electron microprobe, which cannot detect lighter elements such as hydrogen or lithium. The volume of sample required is also relevant as will not only have implications on the archaeological objects that can be studied but also the kind of studies that can be performed, namely whether they are limited to bulk analyses of the object or whether it is possible to perform spot analyses (diverse points of the same object), which will be of great value for archaeological objects that present variations (like colour or textural variations). The points to analyse can be 
established in a random way, by a regular point network or even guided by variations in chromatic or textural object features.

In the perspectives considered here, the identification of the chemical elements present in the sample would be important even if there are limitations to their quantification as long as it is possible to establish their relative importance. Certain chemical elements might have a marked diagnostic power. For example, the presence of certain elements in minor amounts might be useful to distinguish between sources of the same main substance such as silica raw materials.

There are diverse techniques that can detect the chemical elements that are present in a sample and give ranked or absolute estimations of their abundances in a non-destructive way (in the two senses of the expression used here), both by passive detection of emissions from the sample, as gamma-ray spectrometry (SHACKLEY, 1998) or by assessing the response of the sample to some stimulation, as is done in Instrumental neutron activation analysis (GLASCOCK \& NEFF, 2003), scanning electron microscopy, X-ray fluorescence (LIRITZIS \& ZACHARIAS, 2011) and ion bean analysis such as proton-induced X-ray emission (KIM, 2003, BUGOI ET AL., 2004) and proton-induced gamma emission (BUGOI ET AL., 2004) o, and the choice will depend on the specific chemical elements that one wants to analy- se, their contents on the sample and the sensitivity of the technique to those elements. Techniques that require stimulation might have negative effects on the archaeological objects due to the impact of the stimulating procedure, like those due to radiation exposure (BERTRAND ET AL., 2015). Gamma-ray spectrometry is more limited in terms of application as it is only sensible to isotopes emitting gamma-ray but its passive procedure could have advantages in terms of non-interference with the archaeological object as well as in operational terms.

But the results of the chemical analyses will also be affected by the characteristics of the archaeological object such as the volume (already discussed above), elements contents (a problem that affects all kinds of samples) but also, in the perspective of nondestructive analyses, the morphology of the sample, including the surface irregularity. This can either impede the analyses or limit its quantification potentialities. For example, scanning electron microscopy quantitative analyses require a polished surface for quantification as surface irregularities will affect differently the quantification of different elements. However, depending on the differences, it could still possible to perform comparative ranked analyses (which chemical elements are dominant), which could be very relevant for identification, as is illustrated in Figure 4. 


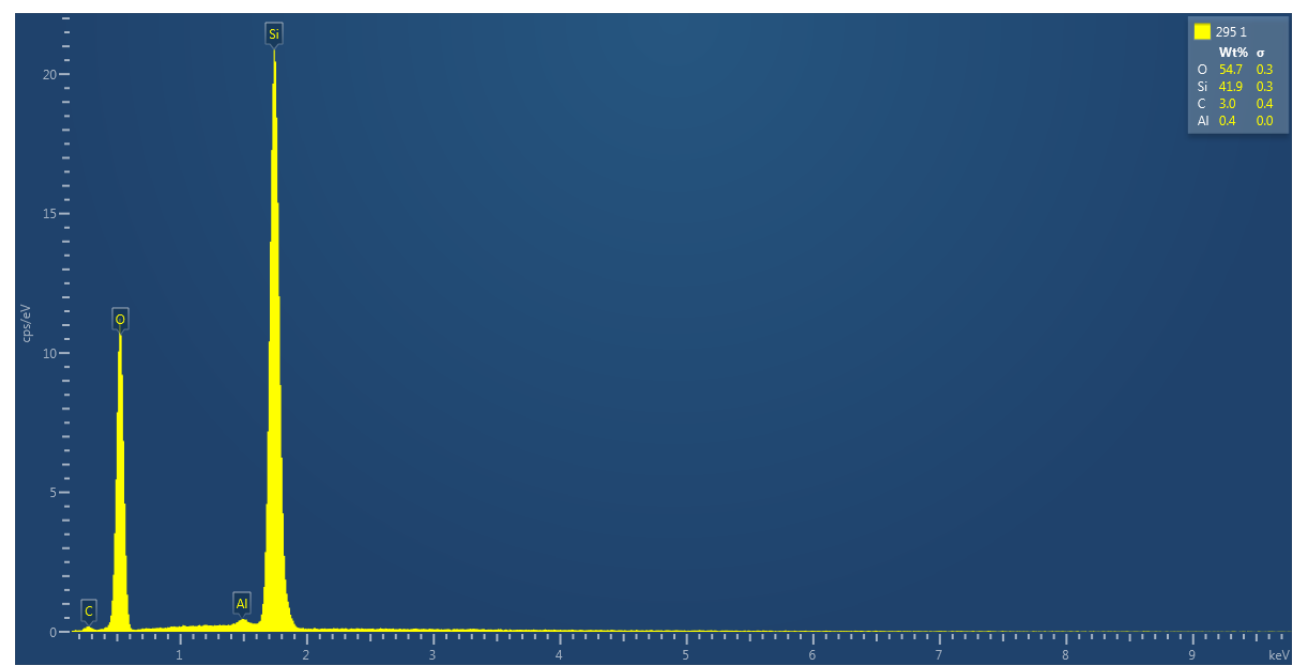

Fig. 4. Chemical Spectrum of scanning electron microscopy of the chert debitage debris of Figure 2.

The depth that is attained by the analytical technique should be considered both in the perspective of attempting to study the portions of the object that are to be analysed and in the perspective of considering the disturbing effects of surface contamination (see example in Figure 1).

There have been some developments in portable applications of diverse techniques for performing chemical analyses on the field. This is very useful for archaeological heritage as it will allow analyses "in situ" removing the potential hazards (and hassles) of transportation. But these portable applications are also very interesting for the study of the potential geological sources, allowing the realization of screening assessments on the variations of chemical features in the geological objects to select sampling points for more detailed analyses.

One can also consider here analyses by laser ablation coupled with inductively coupled plasma mass spectrometry (DUSSUBIEUX ET AL., 2016) which implies the destruction of very small portions of the surface sample (by laser ablation). These techniques could be considered effectively non-destructive in the sense that it will not affect significantly the information value of the archaeological object, as long as that information is based on readings on a scale much larger than the consumed volume (information assessed on a macroscopic level or, in general, with light microscopy). However, this technique could cause some significant impact on features with a volume near the one used by the technique, affecting, for example, the assessment by scanning electron microscopy of marks related to preparation, use and exposition of the artefact. Furthermore, it does not comply strictly with the second sense of nondestructive considered here in the sense that one cannot repeat the analyses exactly in the same spot. It could be argued that this second point is irrelevant in practice and for most objects that will be true but variations on the object could make this point more relevant as it could affect the assessment of whether a gi- 
ven result is in fact due to some analytical or human error (by analyses repetition or comparison with other techniques).

Isotopic analyses for assessing potential sources could be based on stable isotopes but also in radioactive ones when dating the genesis of the geologic material or geologic process that occur afterwards can be used to distinguish between potential sources. Two main possibilities can be considered for the analyses of radioactive isotope proportions: gamma-ray spectrometry and laser ablation coupled with isotope ratio mass spectrometry. Both have already been considered presented above and the questions involved are the same even if the perspective here is to measure isotopes that can give chronological indications. These techniques have been applied (SIMPSON ET AL., 1998; LE ROUX ET AL., 2014) to remains of humans and other animals (bones and teeth) but they should be able to be also useful for geologic raw materials used in the making of archaeological objects.

There could be substances with the same chemical elements and with the same proportions that present significant internal structural differences and these differences could also give information relevant to provenance studies. Spectroscopy techniques such as Raman (EDWARDS \& CHALMERS, 2005) or infrared (NUNZIANTE CESARO \& LEMORINI, 2012) are related to the bonds between atoms and in this manner could be important complements for the chemical analyses (as they could help to identify associations that include elements that are not detected by the chemical analyses). These techniques can also be applied to geological raw materials that are poorly crystalline-like opals or even amorphous - such as obsidian.

\section{FINAL CONSIDERATIONS}

We presented above what we expect was a critical overview of the issues involved in the characterization of geological raw materials used for making prehistoric lithic materials in the perspective of assessing potential sources of those raw materials. We hope to have been able to show that the selection of the techniques for this goal will depend on an interplay of sensitivities:

- Sensitivity of the artefact to the technique;

- Sensitivity of the technique to the characteristics of the artefact that are relevant for the pursued goal.

While the former has been an obvious guide of the considerations presented above, both in terms of selection of concepts presented and of warnings concerning some features of the techniques considered, the later has also been present but deserves to be further developed in these final considerations.

The non-destructive analytical characterization for archaeological artefacts constitutes a hugely complex challenge due to the set of factors mentioned above, such as the variable dimensions of the pieces, their morphologic characteristics (including surface irregularity), problems related to the artefacts previous burial (contamination), as well as the variations in geological characteristics. The suitable characterization techniques need to overcome these difficulties and be able to detect differences in the relevant parameters in a level that discriminate between the potential sources.

A rule of thumb, strongly advised for this kind of studies, will be to first perform tests of the potential techniques on analogues of the archaeological artefact prepa- 
red from raw material obtained in potential sources, in order to assess all the potential implications in terms of the sensitivities just referred. This will require an assessment of both the morphology of the artefact and the geological features suitable for the distinction of potential sources, i.e., features that present differences between potential candidates (the technique need to be sensitive to those differences).

For archaeological objects, and assuming that there are not historical hypotheses to test, comparisons will always be limited to the available geological background knowledge, supplemented by field works in the context of a specific archaeological goal. Limitation criteria will be indispensable to establish a finite set of possibilities and an understanding of the ecosociology of prehistoric humans could give critical information, considering both extension and movement patterns related to physiographic features or biological patterns (of entities which were objects of hunting and gathering).

\section{ACKNOWLEDGEMENTS}

The Lab2PT - Landscapes, Heritage and Territory laboratory - AUR/04509 is supported by the Portuguese "Fundação para a Ciência e a Tecnologia" (Portuguese funds and where applicable the FEDER co-financing, in the aim of the new partnership agreement PT2020 and COMPETE2020 - POCI 010145 FEDER 007528).

Pedro Xavier would like to thank the Fundação para a Ciência e a Tecnologia (Foundation for Science and Technology) for $\mathrm{PhD}$ scholarship, reference (SFRH/ $\mathrm{BD} / 120806 / 2016)$ and to the Unidade de Arqueologia da Universidade do Minho
(UAUM) for the conditions to perform laboratory work.

\section{REFERENCES}

BERTRAND, L., SCHÖEDER, S., ANGLOS, D., BREESE, M. B. H., JANSSENS, K., MOINI, M., SIMON, A. Mitigation strategies for radiation damage in the analysis of ancient materials, TrAC Trends in Analytical Chemistry, 2015, 66, pp. 128-145, https://doi. org/10.1016/j.trac.2014.10.005

BINFORD, L. (1965) Archaeological Systematics and the study of Culture Process. American Antiquity, 31, 203-210. http://www.fafich.ufmg.br/ppgan/wpcontent/uploads/2017/10/1965-Binford. pdf

BUGOI, R., CONSTANTINESCU, B., NEELMEIJER, C., CONSTANTIN, F. (2004) The potential of external IBA and LA-ICP-MS for obsidian elemental characterization. Nuclear Instruments and Methods in Physics Research Section B: Beam Interactions with Materials and Atoms, 26, 136-146. https://doi. org/10.1016/j.nimb.2004.04.185

CLARKE, D.L. (1968) Analytical Archaeology, Methuen, London, United Kingdom, ISBN 0-416-42850-9.

COUSSERAN, S. (2000) L'étude des inclusions fluides appliquée au problème de la circulation des quartz archéologiques dans les Alpes occidentales. [Acquisition de nouvelles données sur les gîtes primaires], Revue d'Archéométrie, 169-177, http://www.persee.fr/doc/arsci_0399-1237_2000_num_24_1_996

DUSSUBIEUX, L., GOLITKO, M., GRATUZE, B. (Eds.) (2016), Recent Advances in Laser Ablation ICP-MS for Archaeo- 
logy. Berlin, Heidelberg: Springer Berlin Heidelberg, https://doi.org/10.1007/9783-662-49894-1

EDWARDS, H.G.M., CHALMERS, J. M. (2005) Raman spectroscopy in archaeology and art history. Cambridge: Royal Society of Chemistry, ISBN: 978-0-85404522-8

GARRISSON, E.G. (2003) Techniques in Archaeological Geology, Springer, Berlin, Germany, 308 p. ISBN 3-540-43822.

GENESTE, J.M. (1991) Systèmes techniques de production lithique: variations techno-économiques dans les processus de réalisation des outillages paléolithiques. Techniques et Culture, Marseille. 17-18, 1-35. https://journals.openedition.org/tc/5013

GLASCOCK, M.D., NEFF, H. (2003) Neutron activation analysis and provenance research in archaeology. Measurement Science and Technology, 14(9), 15161526. https://doi.org/10.1088/09570233/14/9/304

HANSFORD, G. M., TURNER, S. M. R., DEGRYSE, P., SHORTLAND, A.J. (2017) High-resolution X-ray diffraction with no sample preparation, Acta Crystallographica Section A Foundations and Advances, 73(4), 293-311. https:// doi.org/10.1107/S2053273317008592

INIZIAN, M.-L., REDURON-BALLINGER, M.; ROCHE, H., TIXIER, J. (1999) Technology and Terminology of Knapped Stone (Préhistoire de la Pierre Taillée, 5). CREP, Nanterre, $189 \mathrm{pp}$.

KIM, J., SIMON, A. W., RIPOCHE, V., MAYER, J. W., WILKENS, B. (2003) Proton-induced $\mathrm{x}$-ray emission analysis of turquoise artefacts from Salado Platform Mound sites in the Tonto Basin of central Arizona. Measurement
Science and Technology, 14(9), 1579 1589, https://doi.org/10.1088/09570233/14/9/309

LE ROUX, P.J., LEE-THORP, J.A., COPELAND, S.R., SPONHEIMER, M., DE RUITER, D.J. (2014) Strontium isotope analysis of curved tooth enamel surfaces by laser-ablation multi-collector ICPMS. Palaeogeography, Palaeoclimatology, Palaeoecology, 416, 142-149, https:// doi.org/10.1016/j.palaeo.2014.09.007

LEROI-GOURHAN, A. (1971) Évolution et techniques. I. L'Homme et la matière. Paris, Albin Michel, 367 p., 3e éd. revue et corrigée. Portuguese translation, 1984.

LEROI-GOURHAN, A. (1973) Évolution et techniques. II, Milieu et techniques. Paris, Albin Michel, 512 p., 3e éd. revue et corrigée, Portuguese translation, 1984.

LIANG, H. (2012) Advances in multispectral and hyperspectral imaging for archaeology and art conservation, Applied Physics A, 106(2), 309-323. https://doi. org/10.1007/s00339-011-6689-1

LIRITZIS, I., ZACHARIAS, N. (2011) Portable XRF of Archaeological Artifacts: Current Research, Potentials and Limitations,. In M. S. Shackley (Ed.), X-Ray Fluorescence Spectrometry (XRF) in Geoarchaeology, New York, NY: Springer New York, pp. 109-142, https://doi. org/10.1007/978-1-4419-6886-9_6

MANNES, D., SCHMID, F., FREY, J., SCHMIDT-OTT, K., LEHMANN, E. (2015) Combined Neutron and X-ray Imaging for Non-invasive Investigations of Cultural Heritage Objects, Physics Procedia, 69, 653-660, https://doi. org/10.1016/j.phpro.2015.07.092

MEIRELES. J. (2010) Os últimos caçadores-recolectores da Serra da Cabreira (NO de Portugal). O Abrigo 1 de Vale de 
Cerdeira (Vieira do Minho). In A. M. S. Bettencourt, M. I. C. Alves, S. MonteiroRodrigues (eds.). Variações Paleoambientais e Evolução Antrópica no Quaternário do Ocidente Peninsular, pp. 83-96.

MEIRELES, J. (2013) O Abrigo 1 de Vale de Cerdeira, In A.M.S. Bettencourt, $A$ Pré-História do Noroeste Português, A. Cruz \& L. Oosterbeek, Eds., Arkeos 36, Braga/Tomar, pp.116-123

NUNZIANTE CESARO, S., LEMORINI, C. (2012) The function of prehistoric lithic tools: A combined study of usewear analysis and FTIR microspectroscopy, Spectrochimica Acta Part A: Molecular and Biomolecular Spectroscopy, 86, 299-304, https://doi.org/10.1016/j. saa.2011.10.040
ODELL, G. H. (2000) Stone tool research at the end of the millennium: procurement and technology. Journal of Archaeological Research, 84, 261-331

SHACKLEY, M. S. (1998) Gamma Rays, X-Rays and Stone Tools: Some Recent Advances in Archaeological Geochemistry. Journal of Archaeological Science, 25(3), 259-270. https://doi.org/10.1006/ jasc. 1997.0247

SIMPSON, H. P., SCHWARCZ, J. J., STRINGER, C. B. (1998) Neanderthal skeleton from Tabun: U-series data by gamma-ray spectrometry. Journal of $\mathrm{Hu}$ man Evolution, 35(6), 635-645. https:// doi.org/10.1006/jhev.1998.0252 